\title{
Factors Affecting Parent's Perception on Air Quality-From the Individual to the Community Level
}

\author{
Yulin Guo ${ }^{1,2}$, Fengfeng Liu ${ }^{1,2}$, Yuanan Lu 2,3, Zongfu Mao ${ }^{1,2}$, Hanson $\mathrm{Lu}^{4}$, Yanyan $\mathrm{Wu}^{3}$, \\ Yuanyuan Chu ${ }^{1,2}$, Lichen Yu ${ }^{1,2}$, Yisi Liu ${ }^{1}$, Meng Ren ${ }^{1}$, Na Li ${ }^{1}, \mathrm{Xi}_{\mathrm{C}} \mathrm{Chen}^{1}$ and Hao Xiang ${ }^{1,2, *}$ \\ 1 Department of Epidemiology and Biostatistics, School of Public Health, Wuhan University, \\ 115\# Donghu Road, Wuhan 430071, China; sylvia-guo@foxmail.com (Y.G.); \\ 2014283050041@whu.edu.cn (F.L.); zfmao@126.com (Z.M.); 2014203050033@whu.edu.cn (Y.C.); \\ 2014203050031@whu.edu.cn (L.Y.); roselewis@sina.com (Y.L.); melodyren@126.com (M.R.); \\ 2012302170047@whu.edu.cn (N.L.); aries_c_7@163.com (X.C.) \\ 2 Global Health Institute, Wuhan University, 115\# Donghu Road, Wuhan 430071, China; yuanan@hawaii.edu \\ 3 Environmental Health Laboratory, Department of Public Health Sciences, University of Hawaii at Mānoa, \\ 1960 East-West Road, Honolulu, HI 96822, USA; yywu@hawaii.edu \\ 4 International Baccalaureate Diploma Program, Wuhan Foreign Languages School, Wan Song Yuan Road, \\ Wuhan 430022, China; hansonlu_hl@hotmail.com \\ * Correspondence: xianghao@whu.edu.cn; Tel.: +86-27-6875-9118; Fax: +86-27-6875-8648
}

Academic Editor: Paul B. Tchounwou

Received: 26 February 2016; Accepted: 6 May 2016; Published: 12 May 2016

\begin{abstract}
The perception of air quality significantly affects the acceptance of the public of the government's environmental policies. The aim of this research is to explore the relationship between the perception of the air quality of parents and scientific monitoring data and to analyze the factors that affect parents' perceptions. Scientific data of air quality were obtained from Wuhan's environmental condition reports. One thousand parents were investigated for their knowledge and perception of air quality. Scientific data show that the air quality of Wuhan follows an improving trend in general, while most participants believed that the air quality of Wuhan has deteriorated, which indicates a significant difference between public perception and reality. On the individual level, respondents with an age of 40 or above ( 40 or above: OR $=3.252 ; 95 \%$ CI: $1.170-9.040$ ), a higher educational level (college and above: OR $=7.598 ; 95 \%$ CI: $2.244-25.732$ ) or children with poor healthy conditions (poor: $\mathrm{OR}=6.864 ; 95 \% \mathrm{CI}$ : 2.212-21.302) have much more negative perception of air quality. On the community level, industrial facilities, vehicles and city construction have major effects on parents' perception of air quality. Our investigation provides baseline information for environmental policy researchers and makers regarding the public's perception and expectation of air quality and the benefits to the environmental policy completing and enforcing.
\end{abstract}

Keywords: perceived; air quality; factors; individual level; community level

\section{Introduction}

Air pollution in China has become an increasingly severe problem in recent years. A report indicated that in 2013 , only $4.1 \%$ cities among 74 monitored ones met official air pollution standards in terms of $\mathrm{PM}_{2.5}$, with an annual average $\mathrm{PM}_{2.5}$ value of $72 \mu \mathrm{g} / \mathrm{m}^{3} ; 14.9 \%$ of these cities met standards in terms of $\mathrm{PM}_{10}$, with an annual average value of $118 \mu \mathrm{g} / \mathrm{m}^{3}$ [1]. The association between air quality and respiratory diseases has been widely studied, and it is proven that air pollution is an important risk factor for respiratory diseases [2,3]. Children are the most vulnerable population to air pollutants, since they are at the stage of developing their pulmonary functions and physical growth. Moreover, the 
activity energy expenditure (AEE) values of children, especially preschoolers, are significantly higher than those of youths and adults [4]. Because children tend to be exposed to longer hours outdoors than adults [5], air pollution can be a serious health risk to growing children, not only by causing cough, asthma and other respiratory illness, but also inducing adverse pulmonary symptoms [6-8]. Therefore, the assessment of air quality and its health impact is particularly important.

Current information concerning urban air quality in China has been generally based on the measurements from scientific monitoring stations; little attention is paid to the general public regarding their feelings and subjective perceptions of air pollution. Actually, the evaluation of personal perceptions of air quality is an important aspect in life quality and health influence research. Research on air pollution perception, as well as health risk perception are crucial for understanding and predicting the consequences of environment contamination $[9,10]$; it is shown that compared to scientific air quality measurements, personal perception of air quality affects self-reported health conditions to a greater extent [11,12]. The National Environment Monitoring Program of Sweden, for example, has even included annoyance due to air pollution as one of its measures [13].

In many other countries, there were abundant research works about the relationship between perceived air quality and scientific measurements. A previous report indicated that air pollutant annoyance is strongly correlated with indoor concentrations of nitrogen dioxide and sulfur dioxide [14], while other researchers have shown that there is no significant relationship between perceived air quality and scientific measurements. A study conducted by Oglesby et al. in 2009 from Switzerland showed that annoyance at the community level is correlated with the local air quality, whereas annoyance at the individual level is only very weakly correlated with outdoor pollution levels [15]. Current evidence shows that air quality perception can be affected by many other factors, such as gender [13,15], age [16,17], residency status [18,19], level of education $[13,18]$, health condition [13,17], family income [13,15] and household environment [18]. Besides individual-level factors, community-level factors also affect air quality perception. In developing countries, disparity in economic development, boosted by industrial advances, causes an uneven distribution of environment contamination [18]. It has been found that proximity to industrial areas affects the perception of air quality and the health risks of residents $[17,20]$. Residents that live in an area with heavy traffic also have a negative perception of air quality [18].

Wuhan, located in the middle reaches of the Yangtze River, is the largest city in central China. The city's acceleration of industrialization and urbanization, sharp increasing number of automobiles and booming real estate industry pose great challenges to the air quality of Wuhan, which is the most heavily-polluted provincial capital city in southeast China [21]. As its economy develops, the population of Wuhan has rapidly increased by $21.6 \%$ since the last decade according to the sixth census of Wuhan in 2011. However, it is worth noting that the current study into the effects of air pollution on the health of children in Wuhan is generally focused on physiological aspects [22,23], but there is little literature referring to the perception of children's parents on air pollution. Thus, the aim of this survey study is to explore the relationship between the perception of air quality of parents and the results of scientific measurements and to understand the factors that affect parents' perception of air quality.

\section{Methods}

\subsection{Study Subjects}

Through employing convenience sampling, two groups of parents whose children's health conditions are disparate were chosen. The Children's Hospital of Wuhan was chosen as a survey site, as it is the largest children's hospital in Hubei Province. Another survey site was a community in Wuchang district, Wuhan City, the political, cultural and informational center of the whole province. Parents 18 years old or older with children between 1 and 12 years old were randomly surveyed, and they voluntarily took part in the study with the condition that they were fully informed of the aim and details of the research in advance. The sample size of the study was 1000. 


\subsection{Perceived Air Quality and Scientifically-Monitored Air Quality}

The following questions were involved to examine parents' perception of air quality: Compared to the air quality in Wuhan five years ago, how do you think of the air quality now? Candidate answer choices are: much better, better, same, worse, much worse and unsure (have less than 5 years' experience in Wuhan, considering that there are some migrant workers, as well as parents coming from other cities for their children's treatment). Consequently, the responses were dichotomized into two categories: better and worse. Responses of "unsure" were not included for regression analysis. Individual variables affecting parents' perception of air quality concluded: basic information, health condition of child, concern level of air quality; community-level factors came from following question: which of the following do you think is/are the main cause(s) of air pollution in your city or town? Subjects were required to select the top 3 important sources from the above candidates.

The data of the average concentrations of primary air pollutants and the annual excellent rate of air quality in Wuhan city were obtained from the official website of Wuhan Environmental Protection Bureau (Wuhan EPB) [24] and cover the period from 2010-2014. Wuhan EPB established 10 national-level monitoring stations for air quality. Among these 10 monitoring stations, Chenhu Qihao is $40 \mathrm{~km}$ away from the third ring road; it functions as the control sample reflecting the quality of background ambient air, and its data are not used to calculate the city-wide average concentration. The monitoring results of the other 9 monitoring stations are averaged into the city-wide air quality data. The distribution of the 9 monitoring stations is in Figure 1.

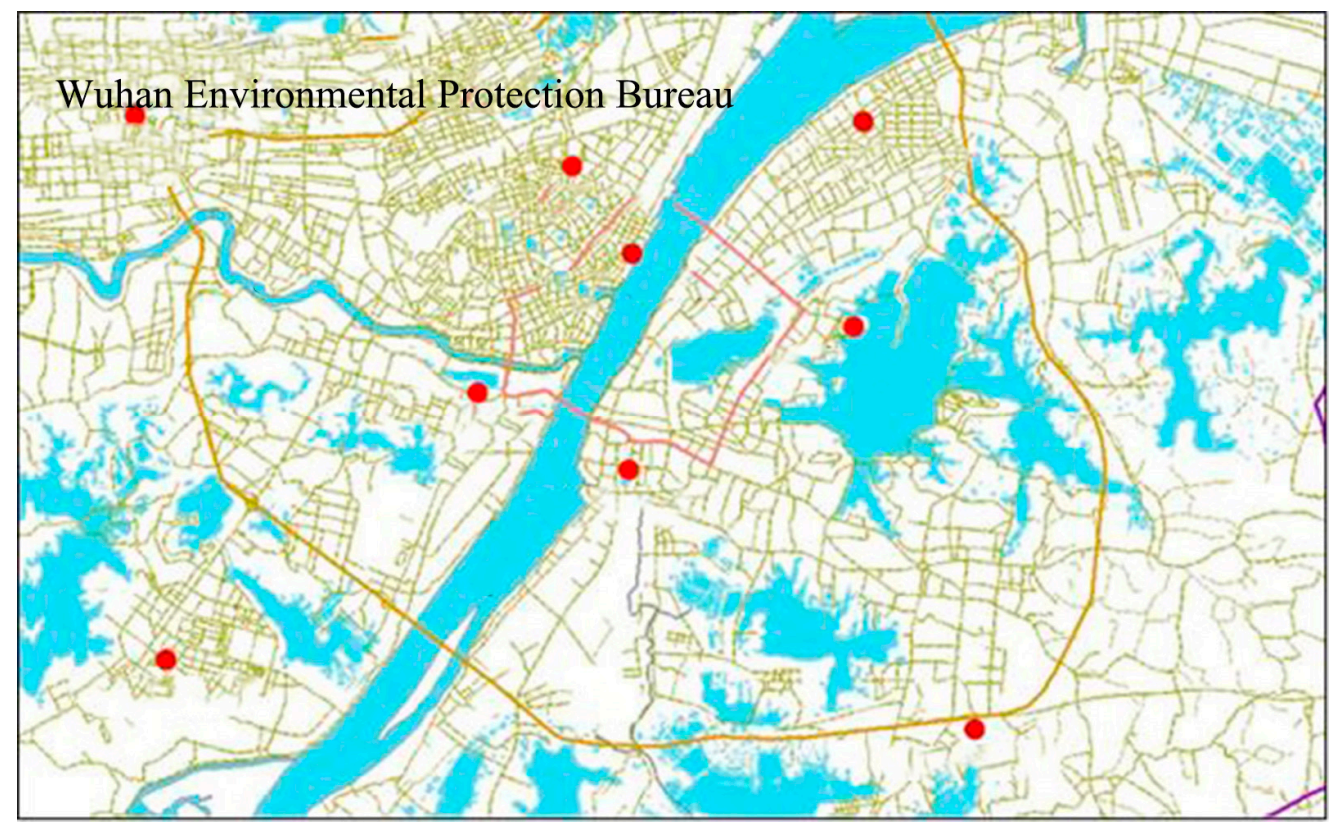

Figure 1. The map of air quality monitoring stations located in Wuhan City.

\subsection{Quality Control}

The questionnaires of this study were designed by experts from the Department of Public Health Sciences, University of Hawai'i. The survey study was conducted by the graduate students and faculty of the School of Public Health of Wuhan University with collaboration with the University of Hawaii. Before carrying out the survey, filling explanations were unified and participant students and faculty members were trained. Two preliminary surveys, each containing 30 questionnaires, were conducted in advance to ensure that questions on the questionnaire could be understood clearly by the respondents. During the survey, the quality control group would examine $10 \%$ of the responses randomly each day to make sure that there were no missed blanks, typographical errors, logical errors and to correct the errors as soon as they were found. 


\subsection{Data Analysis}

Epidata is employed to construct a database, and the double-blind method was used when the data were entered. Ineligible responses with key categorical data missing, such as gender and age, were eliminated. Statistical analysis was conducted by using SAS 9.1 (North Carolina State University, Raleigh, NC, USA). The univariable and multivariable logistic regression model was performed to evaluate the associations between variants and parents' perception of air quality; variates included age, sex, residency status, education level, income, child health condition and degree of concern of air quality. OR and their 95\% CI were calculated as estimates of the correlations, and a value of $p<0.05$ was considered statistically significant in a two-tailed test.

\subsection{Ethical Issues}

This study was approved by the Ethics Review Committee of Wuhan University (NO. 20140212) and the University of Hawaii (NO. 20140414) in accordance with the principles set forth by the Declaration of Helsinki of 1975, revised in 2008. Since the research is focused towards the general public, subjects voluntarily took part in the study with the condition that they were fully informed of the aim and details of the research in advance, and informed consent was obtained from all subjects. Furthermore, the survey was conducted anonymously; the personal information of subjects was not required; and the acquired data were only used for scientific analysis.

\section{Results}

\subsection{General Information of Subjects}

A total of 412 valid responses were collected from Wuhan Children's Hospital and 453 from the community, with a valid returned rate of $82.4 \%$ and $90.6 \%$, respectively. Table 1 shows the demographic data and related information of the subjects.

The gender compositions of the two groups are generally similar. The age of parents from the community is little higher than that of parents surveyed at Wuhan Children's Hospital. The 30-39 years age group was the main part represented in both groups, with $45.6 \%$ of parents from the hospital group and $58.1 \%$ of parents from the community group. Thirty eight-point-eight percent of subjects surveyed at the hospital were in the age group of 18-29 years, while only $4.4 \%$ of respondents from the community group were in this age group. Correspondingly, $37.5 \%$ of respondents from the latter group and only $15.5 \%$ from the former group were 40 years and older.

Most parents surveyed in the community resided in an urban area, with 399 people in total and a ratio of $88.5 \%$. However, 412 respondents, namely, $44.4 \%$ of the hospital group, had an urban residency status and $55.6 \%$ had a rural one.

The educational background of parents from the community group was significantly higher than that from the hospital group. Seventy five-point-one percent of parents from the former group graduated from college, while only $27.7 \%$ of those from the latter group had such a degree of education. Sixty three-point-eight percent of parents surveyed at the hospital had a secondary school education level, and the ratio of elementary school education level is much lower.

Most subjects of the community group had an income of 50,000-150,000 Yuan, composing $64.0 \%$ of the group, whereas this ratio is $45.9 \%$ for the hospital group. Fifty percent of subjects from the hospital group had an income of 50,000 Yuan or below.

The health condition of the children from the community is significantly better than that of those from the hospital $(p<0.01)$. Seventy six-point-eight percent of respondents from the community reported that their child had a good condition, while this ratio is only $40.3 \%$ from the hospital. Correspondingly, $17.5 \%$ of respondents from the hospital reported poor child health, while only $1.8 \%$ of respondents from the community did so.

Among the subjects from the community group and the hospital group, $62.5 \%$ and $53.9 \%$ of subjects indicated a high concern degree for air quality, respectively. 
Table 1. General data of the two population groups.

\begin{tabular}{|c|c|c|c|c|c|}
\hline \multirow{2}{*}{ Item } & \multicolumn{2}{|c|}{ Community $(n=453)$} & \multicolumn{2}{|c|}{ Hospital $(n=412)$} & \multirow{2}{*}{$p$-Value } \\
\hline & $N$ & Percentage & $N$ & Percentage & \\
\hline \multicolumn{6}{|l|}{ Gender } \\
\hline Male & 181 & 40.0 & 187 & 45.4 & 0.11 \\
\hline Female & 272 & 60.0 & 225 & 54.6 & \\
\hline \multicolumn{6}{|l|}{ Age Group (years) } \\
\hline $18-29$ & 20 & 4.4 & 160 & 38.8 & $<0.01$ \\
\hline $30-39$ & 263 & 58.1 & 188 & 45.6 & \\
\hline 40 and above & 170 & 37.5 & 64 & 15.5 & \\
\hline \multicolumn{6}{|l|}{ Residency Status } \\
\hline Rural & 52 & 11.5 & 229 & 55.6 & $<0.01$ \\
\hline Urban & 401 & 88.5 & 183 & 44.4 & \\
\hline \multicolumn{6}{|l|}{ Education Level } \\
\hline Elementary school & 28 & 6.2 & 35 & 8.5 & $<0.01$ \\
\hline Secondary school & 85 & 18.8 & 263 & 63.8 & \\
\hline College and above & 340 & 75.1 & 114 & 27.7 & \\
\hline \multicolumn{6}{|c|}{ Annual Family Income (Yuan) } \\
\hline$<50,000$ & 80 & 20.4 & 206 & 50.0 & $<0.01$ \\
\hline $50,000-15,000$ & 251 & 64.0 & 189 & 45.9 & \\
\hline$>15,000$ & 61 & 15.6 & 17 & 4.1 & \\
\hline \multicolumn{6}{|c|}{ Health Condition of Child } \\
\hline Good & 348 & 76.8 & 166 & 40.3 & $<0.01$ \\
\hline Moderate & 97 & 21.4 & 174 & 42.2 & \\
\hline Poor & 8 & 1.8 & 72 & 17.5 & \\
\hline \multicolumn{6}{|c|}{ Degree of Concern of Air Quality } \\
\hline Rather concerned & 17 & 3.7 & 16 & 3.9 & $<0.05$ \\
\hline Concerned & 153 & 33.8 & 174 & 42.2 & \\
\hline Highly concerned & 283 & 62.5 & 222 & 53.9 & \\
\hline
\end{tabular}

\subsection{Analysis of Scientific Measurements of Air Quality in Wuhan}

\subsubsection{Annual Excellent Rate of Air Quality}

The annual excellent rate of air quality of Wuhan from 2010-2014 was obtained from annual environmental condition reports. Figure 2 shows that the rate was $77.8 \%$ in 2010, and it is in a general rising tend from 2010-2014, except for the year 2013, with a decline to $70.1 \%$; it reached to $79.9 \%$ in 2014.

\subsubsection{Variations of Average Air Pollutant Concentrations}

$\mathrm{NO}_{2}, \mathrm{SO}_{2}, \mathrm{PM}_{10}, \mathrm{CO}, \mathrm{PM}_{2.5}$ and $\mathrm{O}_{3}$ are the main pollutants monitored at the stations in Wuhan currently. CO, $\mathrm{PM}_{2.5}$ and $\mathrm{O}_{3}$ were newly listed as monitored pollutants in 2013. From 2010-2012, concentrations of $\mathrm{NO}_{2}, \mathrm{SO}_{2}$ and $\mathrm{PM}_{10}$ have been steadily declining, but suddenly increased and reached a peak value in 2013 and then declined sharply in 2014, as shown in Figure 3. The average concentration of $\mathrm{PM}_{2.5}$ was $94 \mu \mathrm{g} / \mathrm{m}^{3}$ and for $\mathrm{PM}_{10}$ was $124 \mu \mathrm{g} / \mathrm{m}^{3}$ in 2013, representing a value 1.7- and 1.8-times higher than the standard levels of $\mathrm{PM}_{2.5}$ and $\mathrm{PM}_{10}$, respectively. In 2014, the average $\mathrm{PM}_{2.5}$ concentration dropped to $82 \mu \mathrm{g} / \mathrm{m}^{3}$, and the $\mathrm{PM}_{10}$ average concentration declined to $113 \mu \mathrm{g} / \mathrm{m}^{3}$, which are still much higher (1.34- and 1.61-times) than the standard levels. 


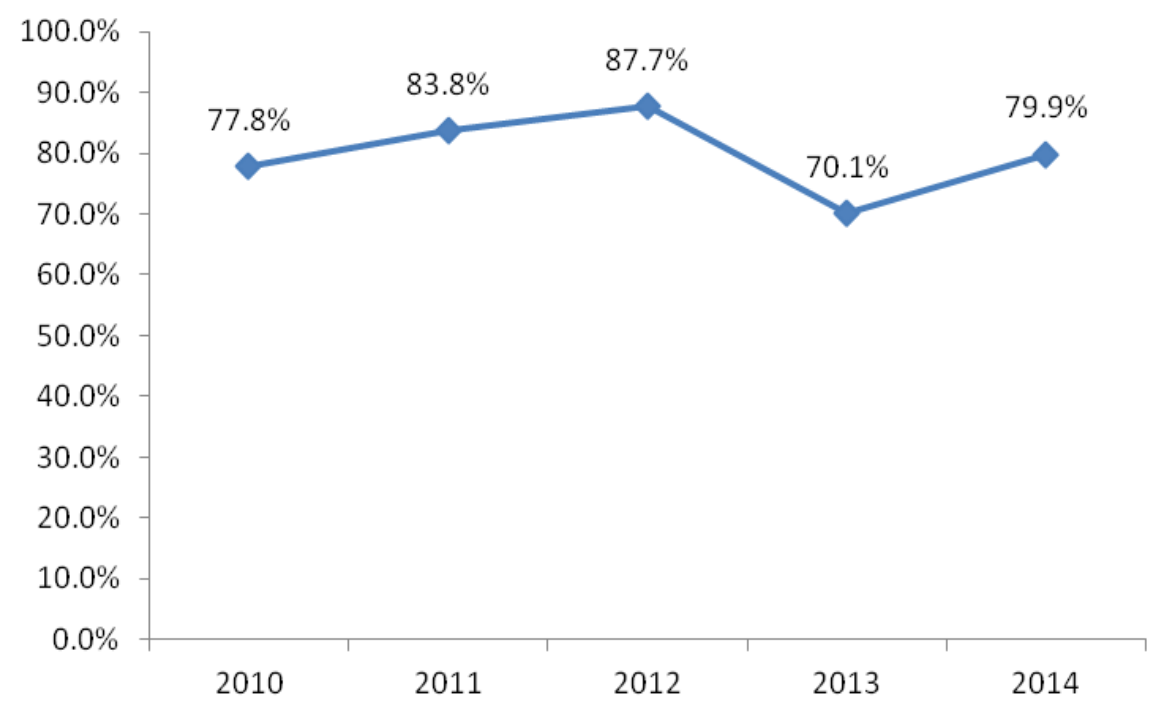

Figure 2. Variations of the annual excellent rate of air quality of Wuhan from 2010-2014.

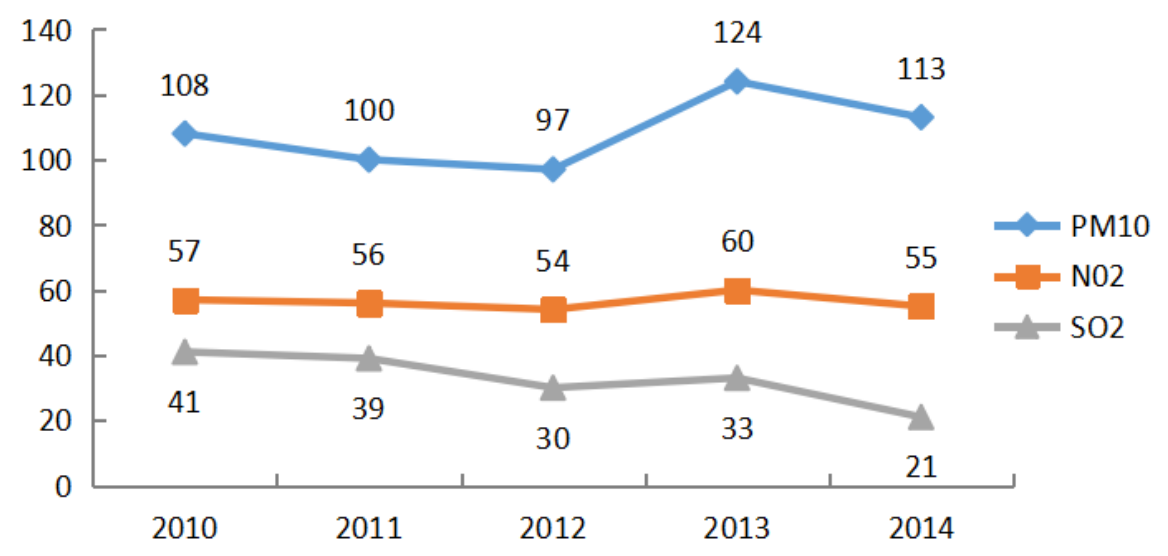

Figure 3. Variations of main air pollutant concentrations in Wuhan from 2010-2014.

\subsubsection{Analysis of Parents' Perception of Air Quality}

The result of the perception of air quality between 2010 and 2014 shows that $84.3 \%$ of parents surveyed in the community and $74.2 \%$ of those surveyed at the hospital considered that the air quality has become worse. Therefore, most parents believe that the air quality in Wuhan has deteriorated in the past five years.

Table 2 shows logistic regression outcomes of air pollution perception of parents surveyed in the community at the individual level. Both univariate logistic regression and multilevel logistic regression analysis showed significant correlations between the perceptions of air quality of the respondents and their education level; the higher the education level of parents, the worse is the perception of parents of air quality.

Table 3 shows logistic regression outcomes of the air pollution perception of parents surveyed at the hospital at the individual level. Both univariate logistic regression and multilevel logistic regression analysis revealed that subjects' perceptions of air quality are significantly correlated to their age, resident area, education level and the health condition of their children. Subjects with an age of 40 years or above, urban resident area, college or above education level and poor child health condition have a worse perceived air quality. In addition, univariate logistic regression analysis shows that there are significant correlations between the perceptions of air quality of the respondents and their resident area; however, in the multilevel logistic regression analysis, there is no association between them. 
Table 2. Logistic regression analysis (OR and 95\% CI) for air quality perception: at the individual level in the community group.

\begin{tabular}{|c|c|c|c|c|c|}
\hline \multirow{3}{*}{ Item } & \multirow{3}{*}{ Total N (\%) } & \multicolumn{2}{|c|}{ Air Quality Perception } & \multirow{3}{*}{ Crude OR $(95 \%$ CI) } & \multirow{3}{*}{ Adjusted OR (95\% CI) } \\
\hline & & Better $(N / \%)$ & Worse $(N / \%)$ & & \\
\hline & & $69(15.7)$ & $371(84.3)$ & & \\
\hline \multicolumn{6}{|l|}{ Gender } \\
\hline Male & $178(40.4)$ & $31(44.9)$ & $147(39.6)$ & Ref. & Ref. \\
\hline Female & $262(59.6)$ & $38(55.1)$ & $224(60.4)$ & $1.243(0.741,2.087)$ & $0.947(0.539,1.666)$ \\
\hline \multicolumn{6}{|l|}{ Age Group (years) } \\
\hline $18-29$ & $16(3.6)$ & $2(2.9)$ & $14(3.8)$ & Ref. & Ref. \\
\hline $30-39$ & $256(58.2)$ & $32(46.4)$ & $224(60.4)$ & $1.000(0.217,4.605)$ & $1.384(0.280,6.834)$ \\
\hline 40 and above & $168(38.2)$ & $35(50.7)$ & $133(35.8)$ & $0.543(0.118,2.501)$ & $0.785(0.158,3.889)$ \\
\hline \multicolumn{6}{|l|}{ Residential Status } \\
\hline Rural & $52(11.8)$ & $9(13.0)$ & 43 (11.6) & Ref. & Ref. \\
\hline Urban & $388(88.2)$ & $60(87.0)$ & $328(88.4)$ & $1.144(0.530,2.470)$ & $1.007(0.529,1.918)$ \\
\hline \multicolumn{6}{|l|}{ Education Level } \\
\hline Elementary school & $28(6.4)$ & $11(15.9)$ & $17(4.6)$ & Ref. & Ref. \\
\hline Secondary school & $83(18.9)$ & $12(17.4)$ & $71(19.1)$ & $3.828(1.445,10.144)$ & $4.164(1.491,11.628)^{* *}$ \\
\hline College and above & $329(74.8)$ & $46(66.7)$ & $283(76.3)$ & $3.981(1.753,9.038)^{* *}$ & $4.034(1.610,10.110)^{* *}$ \\
\hline \multicolumn{6}{|l|}{ Child Health Condition } \\
\hline Good & $336(76.4)$ & $51(73.9)$ & $285(76.8)$ & Ref. & Ref. \\
\hline Moderate & $96(21.8)$ & $16(23.2)$ & 80 (21.6) & $0.895(0.484,1.653)$ & $0.956(0.503,1.814)$ \\
\hline Poor & $8(1.8)$ & $2(2.9)$ & $6(1.6)$ & $0.537(0.105,2.734)$ & $0.570(0.106,3.053)$ \\
\hline \multicolumn{6}{|c|}{ Annual Family Income (Yuan) } \\
\hline$<50,000$ & $79(18.0)$ & $15(21.7)$ & $64(17.3)$ & Ref. & Ref. \\
\hline $50,000-150,000$ & $242(55.0)$ & $39(56.5)$ & $203(54.7)$ & $1.220(0.632,2.357)$ & $1.207(0.609,2.393)$ \\
\hline$>150,000$ & $61(13.9)$ & $7(10.1)$ & $54(14.5)$ & $1.808(0.687,4.758)$ & $1.523(0.557,4.162)$ \\
\hline Unknown & $58(13.1)$ & $8(11.6)$ & $50(13.5)$ & $1.465(0.575,3.729)$ & $1.759(0.642,4.817)$ \\
\hline \multicolumn{6}{|c|}{ Degree of Concern of Air Quality } \\
\hline Rather concerned & $16(3.6)$ & $2(2.9)$ & $14(3.8)$ & Ref. & Ref. \\
\hline Concerned & $146(33.2)$ & $31(44.9)$ & $115(31.0)$ & $0.530(0.114,2.457)$ & $0.481(0.098,2.352)$ \\
\hline Highly concerned & $278(63.2)$ & $36(52.2)$ & $242(65.2)$ & $0.960(0.210,4.401)$ & $0.838(0.172,4.076)$ \\
\hline
\end{tabular}


Table 3. Logistic regression analysis (OR and 95\% CI) for air quality perception: at the individual level of the hospital group.

\begin{tabular}{|c|c|c|c|c|c|}
\hline \multirow{3}{*}{ Item } & \multirow{3}{*}{ Total N (\%) } & \multicolumn{2}{|c|}{ Air Quality Perception } & \multirow{3}{*}{ Crude OR (95\% CI) } & \multirow{3}{*}{ Adjusted OR (95\% CI) } \\
\hline & & Better $(N / \%)$ & Worse $(N / \%)$ & & \\
\hline & & 77 (25.8) & $222(74.2)$ & & \\
\hline \multicolumn{6}{|l|}{ Gender } \\
\hline Male & $133(44.5)$ & $36(46.8)$ & $97(43.7)$ & Ref. & Ref. \\
\hline Female & $166(55.5)$ & $41(53.2)$ & $125(56.3)$ & $1.132(0.672,1.904)$ & $1.230(0.685,2.208)$ \\
\hline \multicolumn{6}{|l|}{ Age Group (years) } \\
\hline $18-29$ & $109(36.5)$ & $39(50.6)$ & $70(31.5)$ & Ref. & Ref. \\
\hline $30-39$ & $142(47.5)$ & $31(40.3)$ & $111(50.0)$ & $1.995(1.141,3.487) *$ & $1.922(1.024,3.605)$ * \\
\hline 40 and above & $48(16.0)$ & $7(9.1)$ & $41(18.5)$ & $3.263(1.337,7.963)^{* *}$ & $3.252(1.170,9.040) *$ \\
\hline \multicolumn{6}{|l|}{ Residency Status } \\
\hline Rural & $144(48.2)$ & 47 (61.0) & $97(43.7)$ & Ref. & Ref. \\
\hline Urban & $155(51.8)$ & $30(39.0)$ & $125(56.3)$ & $2.019(1.189,3.427)^{* *}$ & $1.007(0.529,1.918)$ \\
\hline \multicolumn{6}{|l|}{ Education Level } \\
\hline Elementary school & $21(7.0)$ & $10(13.0)$ & $11(5.0)$ & Ref. & Ref. \\
\hline Secondary school & $180(60.2)$ & $57(74.0)$ & $123(55.4)$ & $1.962(0.788,4.884)$ & $1.879(0.678,5.210)$ \\
\hline College and above & $98(32.8)$ & $10(13.0)$ & $88(39.6)$ & $7.997(2.722,23.489)^{* *}$ & $7.598(2.244,25.732) * *$ \\
\hline \multicolumn{6}{|c|}{ Child Health Condition } \\
\hline Good & $117(39.1)$ & $42(54.5)$ & $75(33.8)$ & Ref. & Ref. \\
\hline Moderate & $130(43.5)$ & $31(40.3)$ & $99(44.6)$ & $1.788(1.029,3.108)^{*}$ & $1.779(0.978,3.237)$ \\
\hline Poor & $52(17.4)$ & $4(5.2)$ & 48 (21.6) & $6.720(2.265,19.941)^{* *}$ & $6.864(2.212,21.302)^{* *}$ \\
\hline \multicolumn{6}{|c|}{ Annual Family Income (Yuan) } \\
\hline$<50,000$ & $134(44.8)$ & $42(54.5)$ & $92(41.4)$ & Ref. & Ref. \\
\hline $50,000-150,000$ & $150(50.2)$ & $33(42.9)$ & $117(52.7)$ & $1.619(0.951,2.754)$ & $1.180(0.655,2.127)$ \\
\hline$>150,000$ & $15(5.0)$ & $2(2.6)$ & $13(5.9)$ & $2.967(0.641,13.742)$ & $1.699(0.334,8.645)$ \\
\hline \multicolumn{6}{|c|}{ Degree of Concern of Air Quality } \\
\hline Rather concerned & $10(3.3)$ & $4(5.2)$ & $6(2.7)$ & Ref. & Ref. \\
\hline Concerned & $113(37.8)$ & $29(37.7)$ & $84(37.8)$ & $1.932(0.509,7.333)$ & $1.071(0.254,4.517)$ \\
\hline Highly concerned & $176(58.9)$ & $44(57.1)$ & $132(59.5)$ & $2.001(0.540,7.420)$ & $0.956(0.233,3.921)$ \\
\hline
\end{tabular}

Notes: $\mathrm{OR}=$ odds ratio; $\mathrm{CI}=$ confidence interval. $* p<0.05 ; * * 0<0.01$. 


\subsection{The Effect of Community-Level Factors on Air Quality Perception}

Parents' perception of air quality was not only affected by individual characteristics, but also by community environments. During the survey, the main air pollution sources were analyzed and showed that automobiles, industrial facilities and city construction were chosen by parents as the most important sources of pollution, with ratios of $69.4 \%, 55.7 \%$ and $53.3 \%$, respectively. The result is in agreement with official reports basically. According to a recent primary research on the composition of pollutant particulate sources, external sources make up $20 \%-30 \%$ of the total calculation, and endogenous sources are the main cause of pollution. Such internal sources include industrial and coal emissions, composing about $40 \%$ of all endogenous contaminants, dust pollution, composing approximately $25 \%$, and vehicle emissions, comprising about $20 \%$ [25]. We converted these three factors into quantifiable indicators: the number of motor vehicles, GDP growth and urban construction investment in Wuhan; and then, we searched related information from 2010-2014 and drew out the trends of community-level factors.

Figure 4 shows the trends of community-level factors. According to data released from the City Construction Committee of Wuhan, city construction investments have a steady fast-paced increase in the past five years, with a total of 61 billion Yuan in 2010 to 150 billion Yuan in 2014. Data released by the Statistics Bureau of Wuhan show that the GDP of Wuhan has also followed with a rising trend, from 556.59 billion Yuan in 2010 to 1.0069 trillion Yuan in 2014. Data from the transportation authority of the city indicate that the amount of automobiles in Wuhan has increased from 1.05 million in 2010 to 1.74 million in 2014.



Figure 4. Trends of community-level factors.

\section{Discussion}

Our study is completed with two types of parent populations: one group is the children's parents from a community in Wuchang, and the other is the parents with sick children in Wuhan Children's Hospital. The two groups have significant discrepancies in resident area, showing that over $88 \%(453)$ of parents surveyed in the community lived in urban areas, while only $45 \%$ of the respondents of the hospital group lived in urban areas. Moreover, referring to the cognition of air quality in Wuhan, $27.4 \%$ of the participant parents of the hospital group responded with the choice "unknown" (resided in Wuhan for less than five years). This could largely be due to the majority of the parents from the hospital group not being local residents (Wuhan), and they were mobile people living in the city for less than five years, or they lived in a region close to Wuhan and came to the hospital for their children's sickness. The mobile population of Wuhan has grown significantly in recent years due to the rapid economic development. According to a survey conducted by the Chinese Academy of Sciences in 2013, the floating population of Wuhan reached 2.87 million, of which the majority comes from rural areas [26]. 
According to the environmental reports of Wuhan, it can be concluded that the air quality of Wuhan in 2014 remained the same as it was in 2010, though it experienced a sharp decline in 2013, indicating that the air quality control measurement has been effective. In fact, the sharp decline of air quality in 2013 might be due to numerous nation-wide extreme climate conditions. During the year, record-breaking conditions of hazy weather occurred, which was unprecedentedly frequent and pervasive, appearing at a peak value for the past 52 years [1]. In addition, Zhang and co-workers described that the climate conditions in 2013 were greatly different from other years with relatively low humidity and precipitation, more static weather, and the atmosphere was stagnant, thereby weakening the possibility for pollutants to dissipate [27]. However, parents considered the air quality of Wuhan to be in a worse condition in 2014 compared to 2010. Factors from both individual and community aspects were examined for their effect on their perception, to explain the distinction between the perception and reality.

Comparing the different age groups, we found that the older ones have a more negative perception. This result is inconsistent with the study of Howel et al., which stated that old-age respondents are unlikely to give current air quality a low rating, since they had a worse environmental experience during former decades [16]. This difference may reflect the difference for the age defined by the two studies. In Howel et al.'s survey, 75 years or above is classified into the older age group compared to 40 years or above, which was considered to be old in this study. We infer that the middle-aged (40 years or above) parents were more likely to emphasize health and safety compared to young groups. Moreover, research conducted by Kim et al. in 2012 from Korea showed that subjects at a young age tend to have more negative perceptions of air quality [28]. This population group mainly consists of students, who were more concerned about environmental issues [6].

Univariate logistic regression analysis of resident area shows that parents living in urban areas have a more negative perception of air quality. Literature relating to the effect of resident area on perception of air quality is limited so far. A study conducted in Shanghai in 2013 showed that perception of air quality differed significantly among residents in different districts of the city. The more urbanized the area in which subjects reside, the more serious they believed the smog problem was [19]. Such a disparity is related to heavy vehicle emissions and the density of buildings in city centers. A study conducted by Brody et al. [17] from Houston and Dallas revealed that compared to citizens in urban areas, subjects who lived in rural areas perceived air quality more accurately. However, in the multilevel logistic regression analysis, there is no correlation in resident area, so we consider it as a confounding factor. It has been well proven that urban and rural residents are unequal in terms of their income and education level. In the central region of China, fertility patterns of urban residents also differ from those of rural residents; the former tends to give birth at a later age ( $>30$ years old) $[29,30]$.

This study also demonstrated that parents with high education have a more negative perception of air quality. This may be due to education having an effect on economic, vocational and social status to different extents. This result is consistent with a previous report showing that the cognition of air quality of citizens is related to their education level [31]. In addition, Badland et al. [32] also found that compared to population groups with low education levels, those who receive higher education tend to have a better understanding that air pollution can adversely affect their health and are therefore more concerned about environmental issues. Correspondingly, their perception of air quality is worse.

This study chose a hospital as one site and found that parents whose children have worse health conditions view air quality more negatively. Abundant literature has proven that air pollution exacerbates children's respiratory symptoms [33,34]. Yazdanparast et al. [35] has shown that parents with asthmatic children will tend to be more aware of the hazards of air pollution. These studies provide support for our results.

Personal characteristics of subjects from the two groups are significantly disparate in general. Compared to subjects surveyed at the hospital, community parents are older in age and have a higher level in education and family income. However, though the individual level variables of the two groups 
are different, their concern and awareness of air pollution and perception of air quality are strikingly consistent. Such a trend indicates that air pollution has high awareness among the general public.

At the community level, we analyzed the three main sources of air pollution in Wuhan, namely city construction, industrial facilities and vehicle emissions. By looking at average concentrations of major air pollutants of Wuhan from 2010-2014, we showed that $\mathrm{PM}_{10}$ and $\mathrm{PM}_{2.5}$ had dramatically exceeded the level of health standards since 2013, representing the first two primary air pollutants. Further analysis showed that the main source of $\mathrm{PM}_{10}$ is dust from soil and roads, accounting for about $50 \%$ [36]. In recent years, investment in city construction in Wuhan has greatly increased; there were over 11,000 road construction, civil projects and real estate construction sites in Wuhan in 2015, causing much dust pollution. Previous research showed that subjects are highly aware of visible pollutants, such as dust [37], which led them to have a worse perception of air quality.

A survey conducted in six major cities in China from November 2013-February 2014 (89 days in total) indicated that among these cities, Wuhan has the highest average concentration of $\mathrm{PM}_{2.5}$, reaching a value of $146.15 \mu \mathrm{g} / \mathrm{m}^{3}$, which indicates 1.82-times over the standard level. The survey has also shown that the industrial proportion and the speed of comprehensive development of the city has contributed to the increased $\mathrm{PM}_{2.5}$ concentrations greatly [38]. From 2010-2014, the GDP of Wuhan increased steadily and reached 1.0069 trillion Yuan in 2014. The chemical industry was identified to take the largest proportion of heavy industry and consumes $61.4 \%$ of the total energy in whole city. It is said that the essence of air pollution in Wuhan is $\mathrm{PM}_{2.5}$ [39]. Studies reveal an inverse causal relationship between atmosphere visibility and $\mathrm{PM}_{2.5}$ concentration [40,41]. Since 2012, $\mathrm{PM}_{2.5}$ has been listed as one of the monitored pollutants by the newly-revised Ambient Air Quality Standards [10] and has widely attracted media and public attention. "Haze" became the keyword in 2013 due to the severe and prevalent smoggy weather. We may therefore deduce that deteriorated weather caused by industrial development and the exhaustive reports by the media on $\mathrm{PM}_{2.5}$ caused children's parents to have a more negative impression of air quality.

With the improvement of living standards, the amount of automobiles in Wuhan has increased from 1.046 million in 2010 to 1.742 million in 2014. Nitrogen oxide emitted from automobiles contributes to $31.1 \%$ of the total amount, but in fact, its concentration has been following a general decreasing trend, thanks to effective air pollution control measures, such as outlawing yellow-labeled vehicles (vehicles with high emission levels). However, residents of Wuhan still tend to attribute air pollution primarily to automobiles today, and this tendency may be caused by the traffic congestion due to the increase in the amount of vehicles. The literature has shown that residents living near heavy traffic have a more negative impression of air quality [13].

\section{Conclusions}

Our research shows that in general, subjects have a negative impression of air quality, which differs greatly from scientific measurements. Through statistical analysis, we found that at the individual level, perception is significantly correlated with resident area, age, education level and the health condition of their children. At the community level, public perception is affected by automobiles, industrial facilities and city construction. Although there is a complex variety of factors, the subjects from both groups are paying great attention to air pollution. In addition, their perception of air quality is an important factor for their acceptance of environment policies set by the government. In fact, the local government has made great efforts to improve the air quality in recent years and brought results, but in this survey, the public perceived that air quality has been deteriorating continuously. Some Chinese scholars have already proposed that the survey and analysis of the air quality satisfactory rate in cities can be a supplement to scientific monitoring in terms of evaluating urban air quality and the effectiveness of government control measurement [42]. Our findings may help policy makers to ascertain a clearer understanding of the relationship between the perception of the general public towards air pollution and scientific measurements and assist them in the dissemination of necessary information to the general public for the better feasibility of their policies. 


\section{Limitations of Our Research}

In our research, only two survey sites were selected, and the research was not conducted on the whole population of Wuhan; therefore, the sample range should be enlarged. Regarding the analysis of air quality in the recent five years of Wuhan, $\mathrm{PM}_{2.5}$ concentrations, an important measurement in evaluating air quality, were only used in 2013 and 2014, due to the lack of data prior to 2013. In the hospital, we mainly carried out the survey in the department of respiratory diseases; we made sure that the majority of children were suffering from respiratory diseases, while we did not collect the children's diseases. If information on the specific category and extent of the disease of children with a poor health condition were collected, in the analysis of the health condition of children, the accuracy of the results of our research may be improved. In future research, these problems may be improved, and more individual- and community-level factors may be included.

Acknowledgments: Thanks for the support from the National Natural Science Foundation of China (Grant No. 81402743), the Hubei Province Health and Family Planning Scientific Research Project (Grant No. WJ2015Q023) and the Fundamental Research Funds for the Central Universities (Grant No. 2042016kf0165). The authors wish to thank Wenyuan Yu for her careful edits and comments.

Author Contributions: Hao Xiang, Yuanan Lu and Zongfu Mao conceived of and designed the research. Yulin Guo, Yanyan Wu designed the methods and analyzed the data. Yulin Guo, Fengfeng Liu and Hanson Lu contributed to the manuscript writing and interpretation. Yuanyuan Chu, Lichen Yu, Yisi Liu, Meng Ren, Na Li and Xi Chen participated in the investigations. All authors reviewed the manuscript.

Conflicts of Interest: The authors declare no conflict of interest.

\section{References}

1. Wang, G.C.; Wang, P.C. PM $_{2.5}$ Pollution in China and its harmfulness to human health. Sci. Technol. Rev. 2014, 32, 72-78.

2. Trasande, L.; Thurston, G.D. The role of air pollution in asthma and other pediatric morbidities. J. Allergy Clin. Immunol. 2005, 115, 689-699. [CrossRef] [PubMed]

3. Chen, H.; Goldberg, M.S.; Villeneuve, P.J. A systematic review of the relation between long-term exposure to ambient air pollution and chronic diseases. Rev. Environ. Health 2008, 23, 243-297. [PubMed]

4. Sigmund, E.; De Ste Croix, M.; Miklánková, L.; Frömel, K. Physical activity patterns of children in comparison to teenagers and young adults. Eur. J. Public Health 2007, 17, 646-651. [CrossRef] [PubMed]

5. Moya, J.; Bearer, C.F.; Etzel, R.A. Children's behavior and physiology and how it affects exposure to environmental contaminants. Pediatrics 2004, 113, 996-1006. [PubMed]

6. Esposito, S.; Tenconi, R.; Lelii, M.; Preti, V.; Nazzari, E.; Consolo, S.; Patria, M.F. Possible molecular mechanisms linking air pollution and asthma in children. BMC Pulm. Med. 2014, 14. [CrossRef] [PubMed]

7. Rojas-Martinez, R.; Perez-Padilla, R.; Olaiz-Fernandez, G.; Mendoza-Alvarado, L.; Moreno-Macias, H.; Fortoul, T.; McDonnell, W.; Loomis, D.; Romieu, I. Lung function growth in children with long-term exposure to air pollutants in Mexico City. Am. J. Respir. Crit. Care Med. 2007, 176, 377-384. [CrossRef] [PubMed]

8. Schultz, E.S.; Gruzieva, O.; Bellander, T.; Bottai, M.; Hallberg, J.; Kull, I.; Svartengren, M.; Melén, E.; Pershagen, G. Traffic-related air pollution and lung function in children at 8 years of age: A birth cohort study. Am. J. Respir. Crit. Care Med. 2012, 186, 1286-1291. [CrossRef] [PubMed]

9. Stenlund, T.; Garvill, J.; Nordin, S.; Andersson, K.; Liden, E. Annoyance and health symptoms and their influencing factors: A population-based air pollution intervention study. Public Health 2009, 123, 339-345. [CrossRef] [PubMed]

10. Zhou, M.; He, G.; Liu, Y.; Yin, P.; Li, Y.; Kan, H.; Fan, M.; Xue, A.; Fan, M. The associations between ambient air pollution and adult respiratory mortality in 32 major Chinese cities, 2006-2010. Environ. Res. 2015, 137, 278-286. [CrossRef] [PubMed]

11. Piro, F.N.; Madsen, C.; Nafstad, P.; Naess, Q.; Claussen, B. A comparison of self- reported air pollution problems and GIS-modeled levels of air pollution in people with and without chronic diseases. Environ Health 2008, 7, 1-10. [CrossRef] [PubMed] 
12. Yen, I.H.; Yelin, E.H.; Katz, P.; Eisner, M.D.; Blanc, P.D. Perceived neighborhood problems and quality of life, physical functioning, and depressive symptoms among adults with asthma. Am. J. Public Health 2006, 96, 873-879. [CrossRef] [PubMed]

13. Jacquemin, B.; Sunyer, J.; Forsberg, B.; Götschi, T.; Bayer-Oglesby, L.; Ackermann-Liebrich, U.; de Marco, R.; Heinrich, J.; Jarvis, D.; Torén, K.; et al. Annoyance due to air pollution in Europe. Int. J. Epidemiol. 2007, 36, 809-820. [CrossRef] [PubMed]

14. Atari, D.O.; Luqinaah, I.N.; Fung, K. The relationship between odour annoyance scores and modelled ambient air pollution in Sarnia, “Chemical Valley”, Ontario. Environ. Res. Public Health 2009, 6, 2655-2675. [CrossRef] [PubMed]

15. Oglesby, L.; Künzli, N.; Monn, C.; Schindler, C.; Ackermann-Liebrich, U.; Leuenberger, P. Validity of annoyance scores for estimation of long term air pollution exposure in epidemiologic studies: The Swiss Study on Air Pollution and Lung Diseases in Adults (SAPALDIA). Am. J. Epidemiol. 2000, 152, 75-83. [CrossRef] [PubMed]

16. Howel, D.; Moffatt, S.; Bush, J.; Dunn, C.E.; Prince, H. Public views on the links between air pollution and health in Northeast England. Environ. Res. 2003, 91, 163-171. [CrossRef]

17. Brody, S.D.; Peck, B.M.; Highfield, W.E. Examining localized patterns of air quality perception in Texas: A spatial and statistical analysis. Risk Anal. 2004, 6, 1561-1574. [CrossRef] [PubMed]

18. Kohlhuber, M.; Mielck, A.; Weiland, S.K.; Bolte, G. Social inequality in perceived environmental exposures in relation to housing conditions in Germany. Environ. Res. 2006, 101, 246-255. [CrossRef] [PubMed]

19. Xie, Y.G. China's Survey Report on Haze in 2013; New Media and Society; Shanghai Jiao Tong University: Shanghai, China, 2013; pp. 156-175.

20. Omanga, E.; Ulmer, L.; Berhane, Z.; Gatari, M. Industrial air pollution in rural Kenya: Community awareness, risk perception and associations between risk variables. BMC Public Health 2014, 14, 377. [CrossRef] [PubMed]

21. Wang, Y.G.; Ying, Q.; Hu, J.L.; Zhang, H.L. Spatial and temporal variations of six criteria air pollutants in 31 provincial capital cities in China during 2013-2014. Environ. Int. 2014, 73, 413-422. [CrossRef] [PubMed]

22. He, Q.Q. Effects of ambient air pollution on lung function growth in Chinese schoolchildren. Respir. Med. 2010, 104, 1512-1520. [CrossRef] [PubMed]

23. Qian, Z. Effects of air pollution on children's respiratory health in three Chinese cities. Arch. Environ. Health Int. J. 2000, 55, 126-133. [CrossRef] [PubMed]

24. The Official Website of Wuhan Environmental Protection Bureau. Available online: http://www.whepb.gov. cn (accessed on 9 May 2016).

25. More Than Half All Day Last Year in Wuhan Polluted, Endogenous Contaminants in Air Is Main Cause. 2013. Available online: http://news.xinhuanet.com/overseas/2014--01/20/c_126033740.htm (accessed on 9 May 2016).

26. Floating Population of Wuhan Is Nearly 3 Million. 2013. Available online: http://www.chinadaily.com.cn/ hqgj/jryw/2013-09-26/content_10198536.html (accessed on 9 May 2016).

27. Zhang, R.H.; Li, Q.; Zhang, R.N. Meteorological conditions for the persistent severe fog and haze event over eastern China in January 2013. Sci. China Earth Sci. 2014, 44, 26-35.

28. Kim, M.; Yi, O.; Kim, H. The role of differences in individual and community attributes in perceived air quality. Sci. Total Environ. 2012, 425, 20-26. [CrossRef] [PubMed]

29. Zhang, Q.; Zou, H. Regional inequality in contemporary China. Ann. Econ. Financ. 2012, 13, 119-143.

30. Yao, C.R.; Wu, F.; Li, J.M. Review of fertility desire investigation among rural and urban residents from 2000 to 2008. Popul. J. 2010, 35, 17-22.

31. Egondi, T.; Kyobutungi, C.; Ng, N.; Muindi, K.; Oti, S.; van de Vijver, S.; Ettarh, R.; Rocklöv, J. Community perceptions of air pollution and related health risks in Nairobi Slums. Int. J. Environ. Res. Public Health 2013, 10, 4851-4868. [CrossRef] [PubMed]

32. Badland, H.M.; Duncan, M.J. Perceptions of air pollution during the work-related commute by adults in Queensland, Australia. Atmos. Environ. 2009, 43, 5791-5795. [CrossRef]

33. Esposito, S.; Galeone, C.; Lelii, M.; Longhi, B.; Ascolese, B.; Senatore, L.; Prada, E.; Montinaro, V.; Malerba, S.; Patria, M.F.; et al. Impact of air pollution on respiratory diseases in children with recurrent wheezing or asthma. BMC Pulm. Med. 2014, 130, 1-9. [CrossRef] [PubMed] 
34. Hoek, G.; Pattenden, S.; Willers, S.; Antova, T.; Fabianova, E.; Braun-Fahrländer, C.; Forastiere, F.; Gehring, U.; Luttmann-Gibson, H.; Grize, L.; et al. $\mathrm{PM}_{10}$, and children's respiratory symptoms and lung function in the PATY study. Eur. Respir. J. 2012, 40, 538-547. [CrossRef] [PubMed]

35. Yazdanparast, T.; Seyedmehdi, S.M.; Khalilzadeh, S.; Salehpour, S.; Boloursaz, M.R.; Baghaie, N.; Hassanzad, M.; Velayati, A.A. Knowledge and practice of asthmatic children's parents about daily air quality. Tanaffos 2013, 12, 23-28. [PubMed]

36. Zhu, Z.C.; Kong, L.L.; Xia, K. Analysis of $\mathrm{PM}_{10}$ source in Wuhan and its countermeasures. Environ. Sci. Technol. 2009, 2, 64-67.

37. Wakefield, S.E.; Elliott, S.J.; Cole, D.C.; Eyles, J.D. Environmental risk and (re)action: Air quality, health, and civic involvement in an urban industrial neighbor-hood. Health Place 2001, 7, 163-177. [CrossRef]

38. Ji, L.L.; Chen, C.K.; Wang, N.N. Comparison and analysis on characteristics and causes of $\mathrm{PM}_{2.5}$ pollution in six typical central cities of China. J. Catastrophol. 2014, 29, 230-234.

39. Wu, D. Systematic review about haze weather in China nearly a decade. Acta Sci. Circumst. 2012, 32, $257-269$.

40. Leung, Y.K.; Wu, M.C.; Yeung, K.K. A study on the relationship among visibility, atmospheric suspended particulate concentration and meteorological conditions in Hong Kong. Acta Meteorol. Sin. 2008, 66, 461-469.

41. Zhang, Q.; Quan, J.; Tie, X.; Li, X.; Liu, Q.; Gao, Y.; Zhao, D. Effects of meteorology and secondary particle formation on visibility during heavy haze events in Beijing, China. Sci. Total Environ. 2015, 502, 578-584. [CrossRef] [PubMed]

42. Song, G.J.; Guo, M.Y.; Yin, G.B. Urban air quality management satisfaction evaluation method and case study. Environ. Pollut. Control 2011, 33, 81-86.

(C) 2016 by the authors; licensee MDPI, Basel, Switzerland. This article is an open access article distributed under the terms and conditions of the Creative Commons Attribution (CC-BY) license (http://creativecommons.org/licenses/by/4.0/). 